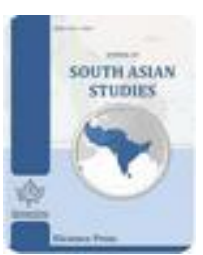

Available Online at EScience Press

Journal of South Asian Studies

ISSN: 2307-4000 (Online), 2308-7846 (Print)

https://esciencepress.net/journals/JSAS

\title{
Militarised Authoritarian State and Informal Institutions: ZuIm and Rasookh in Downtown Srinagar
}

\author{
Touseef Y. Mir \\ School of International Development (DEV), University of East Anglia (UEA), Norwich, United Kingdom.
}

*Corresponding Author Email ID: t.mir@uea.ac.uk

\begin{abstract}
A B S T R A C T
Kashmir is in a situation of protracted conflict. The paper offers an examination of daily life in the downtown of Srinagar, the region's capital. The conceptual focus is on the role of informal institutions, here defined as ordered patterns of behavior, in this setting. A particular concern with how these informal institutions explains how the different residents make sense of the generalized condition of what they term zulm. Zulm refers to the experience of living with, enduring, and engaging with the administration of the militarized authoritarian Indian state, and can be disaggregated into a series of informal institutions deployed by citizens of downtown Srinagar. Based on the ethnographic fieldwork, the paper looks at how differently situated individuals use these institutions - often in the form of networks, economic relationships, connections - to challenge and sustain relations with state structures. The particular focus is given to the informal institution of rasookh. This thesis makes a contribution to the neoinstitutionalist debate within conflict studies by drawing on the social side of the informal institutions. It also contributes to the regional studies literature on South Asia by documenting at close quarters the experience of protracted conflict in Kashmir.
\end{abstract}

Keywords: Informal institutions, Neo-institutionalism, Kashmir, conflict, south Asia, Zulm, rasookh.

\section{INTRODUCTION}

In the protracted conflict of Kashmir, downtown Srinagar has been the site of major episodes of contention in the form of challenging or making claims on the militarised authoritarian state (Tilly, 2006; Tarrow, 2014) - from the plebiscite movement of 1955 (Malik, 2002) to armed militancy of 1989 (Joshi, 1998) to the mass insurrection of 2016 (Geelani, 2019). The cityscape of downtown Srinagar resonates the militarisation of social space (Junaid, 2020a: 5). This becomes manifest in the shape of repressive structures and tactics of the state including, but not limited to, diffused presence of state armed forces, their camps and bunkers, barricades and check posts on roads, alleyways and residential areas, incremental authoritative control on the movement and space of residents (Junaid, 2020a: 4-5). Taken together, these repressive structures arguably contribute to a pervasive sense of being under surveillance among residents of Srinagar. ${ }^{1}$

During my fieldwork in downtown Srinagar from June 2018 to May 2019, my research participants frequently described their experience of living under the repressive structures and procedures of the militarised authoritarian state as 'zulm' - using popular expressions like: zulm karaan (lit doing zulm) and zulmas tal henne' aamit (lit trapped or caught under zulm). The expressions could be understood to delineate two constituent aspects of the pervading social condition of zulm. First being indicative of the exercise of state repression. Second reflecting the experience of the same.

\footnotetext{
${ }^{1}$ The area of Downtown Srinagar falls under the jurisdiction of five police stations - Nowhatta, MR Gunj, Rainawari, Khanyar and Safakadal. Based on the last census, done in 2011, the population of downtown has been estimated to be around three hundred and sixty thousand. For more on the demographics of downtown see https://kashmirreader.com/2021/03/23/a-place-fordowntown-in-smart-city-srinagar/
} 
Thus, zulm embellishes the aspects of exercise, as well as experience of state repression. The paper builds on these two constituent aspects of zulm to unfold how zulm informs the everyday life of different residents under the militarised authoritarian regime in downtown Srinagar.

The online Oxford (Urdu - English) dictionary gives its English equivalents as: cruelty, tyranny, oppression, outrage, injustice. ${ }^{2}$ The following lines from the Amnesty International India website capture the multiple aspects and dimensions of zulm:

And finally, there is zulm or injustice. There is an alternate speech register in Kashmir and the word zulm features right on top for everything India does.

Zulm is broad - zulm starts when you are watched, constantly by the many armies present on the streets. Zulm is being under the gaze.

Zulm continues as curfews are imposed, schools and colleges shut.

Zulm manifests every time a search operation begins

- physical and mental violations of your space by impunity-driven armed forces.

Zulm is being collateral damage. Zulm is being shot by pellets in the body. Zulm is losing sight. Zulm is jumping into the river and drowning because you are afraid.

Zulm is not being allowed to speak to your family. Zulm is also not being allowed to speak for your people.

Zulm is cancelling weddings for the fear of safety of life. Zulm is halting any celebration because last week, your identity was snatched away.

Zulm is not having access to schoolbooks. Zulm is failing clients. Zulm is this month for a girl who can't leave home but had to give an exam online.

Zulm is killing hope.

Zulm is losing an identity.

Zulm is humiliation.

Zulm will live in memory.

(Amnesty International India blog posts of 5th October 2019). ${ }^{3}$

The lines above bolster the argument by depicting how zulm refers simultaneously to the manifestation and

2https://ur.oxforddictionaries.com/translate/urdu-english/ظلم

${ }^{3}$ A detailed account of the write-up titled 'The Many Emotions of Kashmir' can be looked at the link https://amnesty.org.in/the-many-emotions-of-kashmir/ experience of state repression, which entails both a) the manner in which structures and agents of the state exercise militarised authoritarian control, and b) the different ways of living in a militarised society among those who are subject to this control - in this case the residents of downtown Srinagar. Simply put, zulm incorporates within its ambit both, the state-driven expression, as well as the individual-felt experience of the militarised authoritarian control of the Indian state.

In this light, seminal works by Charles Tilly (1977, 2004, 2006) around the interplay of contentious politics and state repression become guiding to understand the interactive dynamic of zulm revealing itself both as expression and experience of militarised authoritarian control. Tilly argues the texture of political regimes to significantly inform the character of contentious politics (Tilly, 2006: 210). He analytically tests the interplay between the said aspects through his two-dimensional space of 'capacity-democracy'. Thus, capacity speaks of the extent to which the regime controls different peoples, as well as their resources and activities and democracy depicts the extent to which individuals possess rights and remedial measures against the arbitrary actions of the regime (Tilly, 2006: 21). As such the location of the regime in the space significantly informs the approach of formal institutions to contentious politics (Tilly, 2006: 211). Seen in the context of downtown Srinagar, the militarised authoritarian regime significantly shrinks the space for contentious politics for different residents in downtown Srinagar. The zulm of its repressive constraints marks their social and physical space. Under such circumstances, informal institutions come through as a significant means of navigating the aforementioned constraints manifesting in the form of the repressive structures and procedures.

It is in this backdrop that the paper explores the informal institutions through which different residents of downtown Srinagar navigate the repressive constraints of zulm in their daily lives with particular focus on the employment of rasookh. The paper underscores rasookh- liaising, building and maintaining good offices with the state (formal institutions) - as significant means of navigating zulm. However, the paper argues that by interplaying with the formal institutions of the state, rasookh may simultaneously reinforce zulm as well. The paper imagines rasookh through the neo-institutionalist perspective (Lauth, 
2000,2004 ) viewing state through the lens of formal institutions - formally codified norm patterns that shape behaviour and in turn social action (Lauth, 2000: 24) and rasookh as an informal institution - informal but socially accepted norm patterns informing their behaviour and consequent social actions (Lauth, 2000: 24-5) - to explore their interplay with respect to the pervading social condition of zulm.

The following sections unpack zulm followed by the section unfolding different elements of violence embellished in zulm. The paper then segues to first unfold rasookh as informal institution and then flag it as a significant means of navigating the repressive constraints of zulm. The next section highlights rasookh as being potent to simultaneously reinforce $\mathrm{zulm}$ followed by the conclusion to the paper summarising the main arguments.

\section{THE (EXERCISE) OF ZULM:}

This aspect of zulm unfolds the exercise and manifestation of state repression in the daily lives of the differently situated residents of downtown Srinagar. In this regard, Tilly (2006) highlights how the formal institutions exercise repression in relation to the contentious politics under authoritarian regimes. He argues repression to be executed to discourage the actors from resorting to contentious politics by raising the costs of acts of contention (Tilly, 2006: 74-81). The repressive measures, as such, serve the authoritarian regimes principally in two ways. Firstly, they (punitively) contain actors of contentious acts. Secondly, the exercise of repression on them serves to discourage others from contentious politics. This as a consequence helps militarised authoritarian regimes to ensconce their rule by shrinking space for contentious politics. Frantz and Kendall-Taylor bolster the argument by arguing state repression in authoritarian contexts (in order to contain contention and give those resorting to acts of contention specific social and political direction) to not only use violent repression but also violate their civil and political rights (ibid. 2014: 333-4).

From this perspective, the pervading social condition of zulm can be argued to comprise not only the violences that are manifest or visible, but also those that are rather invisible. In this light, the distinction of state repression by Jennifer Earl (2003) into its observable and unobservable forms merits attention. While placing the level of visibility on a continuum, Earl argues the former to be the coercive or overt repression that is felt and intended to be known publicly. Whereas, in the latter case, acts and purpose of the repression are intended to be hidden or covert making up the unobservable repression (ibid. Remove ibid throughout the paper and write the author's last name, 2003: 48). Dana Moss (2014) bolsters the argument by echoing repression to most typically be conceived as physical coercion, though building on Tilly's (2006) understanding, she argues state repression to comprise of a repertoire of actions consisting of non-physical aspects as well (2014: 263). In the context of downtown, the violences observed and directly felt can be drawn into the folds of observable repression and the rather invisible or not directly felt violences signify the unobservable forms of state repression. With regard to different violences, the zulm of militarised authoritarian control manifesting observable and unobservable repressions (Earl, 2003) in the daily lives of different residents embellish interrelated and mutually reinforcing elements of violences physical, structural and cultural - (Galtung, 1969, 1990) imbuing the physical and social space of downtown Srinagar.

From this perspective, the execution and manifestation of structures and procedures of state repression in downtown Srinagar, attain meanings broader than physical coercion. Thus, zulm as the exercise of state repression does not only convey the manifestation of physical coercion in the lives of differently situated residents of downtown Srinagar, but non-physical aspects as well. They are equally violent but mostly nonmanifest, broader and blanket in their influence. Put simply, the oeuvre of (observable and unobservable) state repression unfold physical, structural and cultural violences (Galtung, 1969, 1990; Galtung \& Fischer, 2013) in the social and physical spaces of downtown Srinagar.

\section{CONSTITUENT ELEMENTS OF VIOLENCE IN ZULM}

This section unpacks the pervading social condition of zulm (manifested as exercise and experience of observable and unobservable state repression) into its constituent elements of direct, structural and cultural violences (Galtung, 1969, 1990). The said elements animate as sutured together in mutually reinforcing fashions. But, for heuristic purposes they are teased out independently.

\section{Direct violence element of zulm}

Drawing from above, this can be argued to be the 
physical or behavioural element of zulm. It involves use of physical force that can cause potentially severe bodily harm (Galtung, 1990: 294; Brockhill and Cordell, 2019: 983). This form of violence may (or may not) involve use of arms or weapons but has definite visible physical manifestations.

As part of the exercise of zulm by formal institutions, it is more specific, individualised and visible. It incorporates acts of physical coercion like arrests, detentions, torture, killing, sexual violence, cordon and search operations (CASO), frisking, firing live ammunition on civilians, teargassing and pepper gassing in residential areas, rummaging of houses, smashing of windows during search operations, as well as psychological coercion like threats and intimidation.

The exercise of these acts has profound physical and psychological implications for the differently situated residents of downtown. For instance, Ganie (2021) reflecting on the violent state repression in Kashmir states about 1500 people to have suffered serious eyes injuries (including infants as young as 18-months) with 139 to have been fully blinded due to metallic pellets fired by the state armed forces in response to acts of contention between 2016 and 2019. He argues it to be the first state led mass blinding campaign of the world (Ghosh \& Duschinski, 2020: 7).

Likewise, with regard to the psychological ramifications the Médecins Sans Frontières (MSF) report of 2015 becomes telling. The report states one out of every two adults in Kashmir to be mentally disturbed and $41 \%$ of the adult population to have symptoms of clinical depression. It further flags $19 \%$ of the population in Kashmir to be with significant symptoms of PostTraumatic Stress Disorder (PTSD) representing 771,000 individuals. The report states the psychological morbidity rates in women to be increased apart from an overall increase in suicide rates in Kashmir (MSF report, 2015).

Thus, the facts become talking about the humanitarian costs that may be borne in consequence to exercise of direct violence by the militarised authoritarian state in Kashmir at large, with downtown being no exception.

\section{Structural violence element of the exercise of zulm}

In this form of violence, the violence or harm is rendered by the prevalent institutions or structures (social, political or economic) rather than the individuals. Galtung argues structural violence to be the invisible form of violence that has the potential to cause direct violence (Galtung, 1969: 168). In other words, it is the indirect form of violence prevalent in the social, economic and political structures that generate among different people a sense of injustice, inequality or exploitation. Simply put, this aspect of state repression manifests itself among the receiving populations in the shape of deprivation of basic human needs especially survival, identity, well-being and freedom (Brockhill \& Cordell, 2019: 983-4).

In the context of downtown Srinagar, it animates through a complex network of prevalent repressive structures. Its manifestations include militarisation of the landscape (Duschinski \& Hoffman, 2011: 45), profound prevalence of colonial laws such as: armed forces special powers act (AFSPA), unlawful activities prevention act (UAPA), public safety act (PSA) that give the state armed forces significant carte-blanche to act with impunity (Ghosh \& Duschinski, 2020 : 368). Moreover, it embellishes arbitrary executive actions that facilitate banning of social and political outfits ${ }^{4}$, incrimination of peaceful assembly and voicing of democratic dissent, such as internet and communication blackouts or restriction and manipulation of news and information buttressing the everyday experiences of incremental shrinking of the democratic space of expression including the digital space. ${ }^{5}$ The internet and communications blackout in Kashmir in the wake of its dismemberment and relegation into centrally controlled principality, made the UN experts call it out as collective punishment to the people that ought to be reversed. ${ }^{6}$

Such violences augment the popular feelings of powerlessness and victimisation and an overall invisibilization of the pain. For instance, the multiple instances of sexual violence including mass rapes in Kashmir by the armed forces of the state have been denied and played down as propaganda (c.f. Amnesty International Report, 1993; Essar et. al. 2016; Joshi,

\footnotetext{
4 Since at least 2016, Kashmir has witnessed banning of many religious as well as political organisations like Jamat-e-Islami Kashmir and Jammu and Kashmir Liberation Front. Many of the representatives, office bearers and activists the aforementioned organisations and many others have been jailed and their properties raided and sealed as well.

5 The communication blackout imposed by the state in Kashmir in the backdrop of unilaterally revoking of statehood and autonomy on $5^{\text {th }}$ august 2019 lasted more than a year. It emerged to be among the longest blackouts globally.

${ }^{6} \mathrm{~A}$ detailed news of the same may be checked at the UN website: https://news.un.org/en/story/2019/08/1044741
} 
1998). Thus, as argued in the beginning of the section, structural violence wields the potential to cause impediments stymying the course of daily life. As portrayed above, such these violences can not only suspend space, movement and expression of different residents but exercise militarised authoritarian control over their time as well (Junaid, 2020a: 308).

\section{Cultural violence element of the exercise of zulm}

The utilisation of aspects of culture to perpetrate or generate violence (direct or structural) becomes cultural violence. Here the violence unlike structural violence is not embedded in structures but originates from cultural aspects. In other words, the cultural violence modifies the beliefs of the perpetrators of violence to justify and legitimize their acts of violence, appearing to them as natural or not wrong (Galtung, 1990: 291). Brockhill and Cordell argue these aspects to manifest among the impacted populations feelings of discrimination, delegitimization, marginalisation and alienation (Zia, 2019: 984).

With respect to downtown Srinagar, the cultural violences permeate the social and physical spaces. Such violences are predicated by the formal institutions on the premise of protecting national security and integrity legitimising direct and structural violence against different residents. The violences manifest in the shape of Indianisation of bureaucracy, promotion of Indian popular culture through media and educational systems, as well as influx of external businesses at the cost of local ones becoming causal factors for other structural and direct violences including the unabated and unaccounted exploitation of their resources further reinforcing experiences of zulm (Osuri, 2017; Zia, 2019). The cultural violences also include manifest experiences of zulm such as: closing the mosques, restricting prayers, stopping religious processions, vandalising religious spaces or arresting religious preachers. ${ }^{7}$

Moreover, another significant aspect of the cultural violence is the essentialisation and misrepresentation of Kashmiri men as gullible to extremism and violence and

\footnotetext{
7 The recent past has seen escalation in the restriction and closure of main religious centres across Kashmir. For instance, since $5^{\text {th }}$ of August 2019, the Jamia masheed central mosque - in downtown Srinagar has been mostly closed to congregational prayers such as Friday prayers. Likewise, there have been growing restrictions on religious processions like Muharram with many instances of beating and detention of those participating in them by state armed forces.
}

their women as objects of desire (Kaul, 2018: 132). This as a consequence 'opaques' their realities and invisiblises their pains and miseries (Brockhill and Cordell, 2019: 983) confirming to the ends of cultural violences. The essentialisation and objectification of the women as fair skinned and desirable commodities $^{8}$ on one hand and men as inherently violent and extremists on the other faces them with: denial of accommodations in hotels, hostels and apartments in India, frequent and fatal attacks (on students, businessmen and tourists), indictment in fabricated cases. ${ }^{9}$

The experience can be argued add to the sense of powerlessness, marginalisation and collective punishment at large. For instance, the changes in domicile laws and land laws evoke fears of demographic change or genocide. The genocide alert for Kashmir by the US based thinktank genocide watch can be argued bolster the argument. ${ }^{10}$

Following from above, the constituent elements of violence embellished in the pervading social condition of zulm animate to inform the delegitimization of the political rights, peoplehood and humanhood (Zia, 2019: 992) of those faced with these violences, in this case the differently situated residents of downtown Srinagar. It augments their incremental sense of victimisation and collective punishment. In this context, the mid-term report by the Indian civil society group 'forum for Human Rights in Jammu and Kashmir' flags the overwhelming state repression in Kashmir to have caused near-total alienation of the people of Kashmir from Indian state (Forum on Human Rights in Jammu

8 There has been an escalation of commodification and romanisation of Kashmiri women. The agents and intermediaries of the state have mostly been complicit in bolstering such imaginaries. See for instance the statement in a public rally by the chief minister of Indian state of Haryana 'Now We Can Bring Kashmiri Girls for Marriage': Khattar's Comment at BetiBachao Event Sparks Row (news18.com).

Also, there has been a growth in events where Indian armed forces have been caught while abducting and trafficking young Kashmir girls out of Kashmir Army Man With Two Kashmiri Girls Detained At Airport (kashmirlife.net)

9 There are multiple instances where Kashmiri men have been booked under preposterous charges and exonerated after over a decade of illegal imprisonment. For instance, refer to the case of Mirza Nisar from downtown Srinagar exonerated after 23 years of imprisonment after being proven innocent. After 23 years in jail, freedom is a 'different kind of prison' for innocent Kashmiri man (theprint.in)

10 Genocide Alert for Kashmir, India (genocidewatch.com) 
and Kashmir report, 2021: viii).

Thus, the experience of living through the repressive constraints of zulm unravels significant overtones of fear, trauma, loss and an overarching sense of precarity of the physical and social environment in the daily lives of differently situated residents of downtown Srinagar. In this light, the use of informal institutions like rasookh are principally exercised to overcome such precarities and insecurities by some.

\section{Unpacking Rasookh}

Rasookh as discussed above, refers to the practice of building, maintenance and utilisation of good offices with the state (formal institutions) through its agents (officials and intermediaries). As discussed above, the structures and procedures of state repression significantly shrink the space for contentious politics (Tilly, 1978, 2006; Tarrow, 2014) embellishing the pervading social condition of zulm. Rasookh can be argued to attain significance in that backdrop as a means of easing the experience of navigating through its repressive constraints. Moreover, the societal acceptance and normalisation of the practice, particularly in response to zulm emerges it as an informal institution.

The Rekhta ${ }^{11}$ Urdu dictionary, as well as the University of Chicago (Urdu-to-English dictionary) ${ }^{12}$ give the English equivalents of the word as: firmness, stability, steady friendship, influence. In downtown Srinagar, its usage tethers the above meanings to the practice of rasookh. In that context, it takes the form of considerably stable connections (particularly that of friendship or liaison) with the formal institutions through their agents consequently influencing their functions. Simply put, rasookh reflects a conscious effort on part of those employing it to cultivate, curate and make use of their liaisons with the agents of the formal institutions, in order to draw favours vis-à-vis the zulm. The favour in this sense comes in the shape of navigation through the repressive constraints of zulm.

\footnotetext{
11https://www.rekhta.org/urdudictionary/?lang=1\&keyword= رسوخ

12 Lauth's (2000) work also nuances informal institutions based on their relationship with the formal institutions into complimentary, substitutive and conflicting types. In similar vein, Li (2019) in his work highlighting the management, restriction and accommodation of politics of contention in China by the state underscores their selective utilization of accommodating and antagonistic informal institutions.
}

\section{Rasookh as informal institutions}

The paper argues rasookh to analytically unfold as an informal institution. It understands informal institutions from the neo-institutionalist perspective of HansJoachim Lauth $(2000,2004,2015)$ arguing institutions to be nuanced from organisations - as norm patterns that shape behaviour and in turn structure societal action and enhance the security with which citizens can expect reciprocal behaviour from fellow citizens (ibid. 2000: 23). Based on this understanding, Lauth explicates informal institutions as (unofficial and uncodified) norm patterns which shape behaviour, and which in turn structure societal action (2000: 23). In other words, Lauth argues informal institutions as being solely based on the fact of their existence and effectiveness and not being formally codified in written documents (either in constitution or laws) unlike the formal institutions. While the formal institutions receive their legitimacy from state agencies, the legitimacy of informal institutions is predicated on their social acceptance. They persist by virtue of their normalisation or social entrenchment in the human behaviours over the time and sustain through auto-licensing, that is, selfenactment and self-assertion (Lauth, 2000: 24). Moreover, while the violation of formal institutions is sanctioned by the state, for the informal institutions their violation may involve sanctions through social mechanisms like exclusion or minimal access to goods and services.

Put simply, informal institutions can be stated to be the socially accepted, known and normalised patterns of behaviour that persist over time due to their capability of structuring or goading social action. Being different from formal institutions, they do not have a centre to control or direct their actions and owe their existence and recognition to their functional utility without which they cease to exist (Azari and Smith, 2012; Helmke \& Levitsky, 2006; Lauth, 2000; Neudorfer \& Theuerkauf, 2014).

With respect to the employment of rasookh, navigation through the constraints of zulm happens by influencing the 'addressees of the informal institutions' (Lauth, 2000: 25) that is the officials and intermediaries of the state agencies formulating or implementing the policies of zulm. It is by virtue of the connections that functions of formal institutions are influenced through their agents (officials and intermediaries), a process referred as 'strategic interactions' by Helmkey and Levitsky 
(2004: 731). Thus, employment of rasookh exhibits its interplay with the formal institutions influencing their functions as a means of navigating the constraints of zulm. The prevalence and societal acceptance of the practice of rasookh in response the constraints of zulm among the differently situated residents of downtown Srinagar normalise it as an informal institution.

In the wider south Asian context, the employment of rasookh can be argued to find resonance with the scholarly works of Brass (1997) and Jeffrey (2000) and others who portray through their studies how police as well as judicial assistance in north India come to be arbitrarily mediated by the utilisation of different informal institutions like networks (by mostly the rich and upper caste men) within the state (formal institutions) through their agents (officials and intermediaries). Particularly, the ethnographic work of Craig Jeffrey (2000) in the north Indian state of UttarPradesh becomes guiding to bolster the argument about the employment of rasookh in response to zulm in downtown. The study maps how by virtue of their social and economic power the Jatt agriculturalists establish and make use of their informal networks with the local police (Lauth, 2000: 1024). Such informal institutions especially with the police other than serving them establish and reinforce their local dominance (hierarchy and patrimonial structures of dominance) significantly help them escape accountability in front of the law enforcement agencies of the state, for what may be called their extra-legal activities (Lauth, 2000: 1027).

Similar scholarly works depict differently situated men (well placed in the social and economic hierarchy of the society) exercise their influence over the state (formal institutions) through informal institutions like networks or shadow states to maintain their positions, influence their transactions within formal institutions, as well as, have their say in their societies (Harriss-White, 2003; Jeffrey \& Lerche, 2000; Khan, 2008; Krishna, 2006; Pattenden, 2011). The dynamics can as well be seen to echo in the studies conducted by Bayart (1993), Utas (2012) with regard to the post-colonial states of Africa. The studies cited above, depict the prevalence and utility of informal institutions by the rich and affluent men. The studies reflect the role they play in influencing the functions of formal institutions to help them maximise their appropriation of the state resources and services, as well as maintain their patronage in the society.

However, in the context of rasookh, unlike the case of aforementioned studies, the connections are mostly personal than transactional. The aforementioned informal institutions, unlike rasookh, are primarily aimed at seeking or appropriating either the material resources of the state or the maintenance of local patronage or domination. Whereas rasookh is primarily employed in order to navigate the repressive constraints of the pervading social condition of zulm. Also, with regard to the said institutions, the relation between the actors is mostly non-personal, loose and business oriented. However, as argued in case of rasookh, the association is relatively personal and closer, like friendships and personal liaisons.

Moreover, in order to not appear disobedient to the popular contentious politics against the Indian state in downtown Srinagar (Junaid, 2020b: 171), the existence or employment of means like rasookh are not overtly visible to the public gaze or not manifested or boasted as a show of strength in the society, unlike the case in the wider south Asian context where such associations are generally showed off as a mark of strength and maintenance of local patronage as depicted in the studies cited above. Put simply, rasookh in downtown is primarily maintained through close personal contacts in order to respond to and make easy the experience of (living through) the pervading social condition of zulm. It is not however, boasted either as show of strength or maintenance of local patronage. Moreover, as established above, its primary concern remains navigation through the constraints of the pervading social condition of zulm.

\section{Availability of rasookh}

Lauth argues informal institutions to have their own access and boundary rules and the informal institutions with their centre of dominance in the society, like rasookh, to be built on relational relationships (Lauth, 2000: 25-8). Thus, the availability of rasookh with the agents of formal institutions is also not universally available. Drawing from the fieldwork, as well as the aforementioned studies, the ability to employ informal institution of rasookh could be argued to be significantly influenced by one's position in the society. This with regard to downtown Srinagar, apart from other aspects that may be significantly included the situation of the residents in terms of their social situation and occupation.

Thus, the residents with more likelihood or ability to employ rasookh with the formal institutions came 
through to be residents with occupations or businesses that increased their interface with the middle and higher-level bureaucracy. Those included contractors, persons from the media and journalism, representatives of different unions such as traders, manufacturers and civil society groups. Further, some (social or political) activists associated with pro-state organisations also came through as having significant ability to employ rasookh with the agents of formal institutions. Their greater ability to employ rasookh can be argued in terms of their increased interface with the agents (officials and intermediaries) of the state among other reasons that may be. In additions to this, some people by virtue of their familial situation in the society also had greater ability of employing rasookh. This included families that had their kin or relations in the middle or higher-level bureaucracies of the state or associated with pro-state political outfits. Of the many that be, these categories of residents came through as having relatively more ability of employing rasookh with the officials and intermediaries of the state. As reflected in the works of Jefferey depicting how the increased interface with the formal institutions (by virtue of placing members of their family in the bureaucracy and increased interaction with informal networks of state) galvanised appropriation of goods and services of the state by rich Jatt families in Uttar Pradesh, India (ibid. 2000: 1024).

Also, Kashmir being a patriarchal society, with downtown being no exception, rasookh can be argued to be a remarkably masculinised practice. Especially, in the backdrop of multiple instances of sexual abuses against women ascribed to the militarised authoritarian state (Peer, 2008; Dushcinski and Hoffman, 2012; Esaar et al, 2014; Fazili, 2017; Zia, 2019; Amnesty International report, 1993) the association of women with the agents of state is popularly discouraged and looked down upon (Junaid, 2020b: 170). In the words of Fazili, there is a general distrust of agents of state, especially its armed forces, regarding their women (Fazili, 2017: 224). As such, the employment of rasookh flags as an informal institution employed overwhelmingly by men.

\section{Subverting and sustaining zulm: rasookh vis-à-vis formal institutions}

This section unfurls the contradictory role that can be ascribed to the exercise of rasookh. The section argues that albeit rasookh gets employed by some residents as a significant means of navigating the constraints of zulm of the militarised authoritarian control, its exercise ends up buttressing the structural violence aspect of it. The exercise of rasookh ensures participation with formal institutions that exercise zulm ending up internalising the normalisation of their repressive structures and procedures bolstering the structural violence.

Reflecting on the relationship of formal and informal institutions, Helmkey and Levitsky (2004) argue the informal institutions to exert considerable influence on formal institutions where they complement, accommodate, substitute or compete the formal institutions (Helmkey \& Levitsky, 2004: 728-30; 2006: 14). Following from the distinction of Helmkey and Levitsky (2006) rasookh exhibits significant features of a competing informal institutions, which are argued to be the institutions that interplay with the (ineffective) formal institutions and as a consequence of the interplay yield outcomes that are divergent to what could be had by exclusive adherence to the formal rules (Helmkey \& Levitsky, 2004: 728-9). The divergence of the outcomes with regard to rasookh become reflective of the navigation through the pervading social condition of zulm which in the absence of the employment of rasookh would not be as such.

Apparently, the employment of rasookh pinpoints the utilisation of informal institutions under repressive regimes as significant means of navigating the constraints of formal institutions. The result of its employment, as such, addresses the precarities or pervading uncertainties in the social environment, as well as protection against the arbitrariness of actions of the state. However, a critical understanding of the aforementioned informal institution becomes revealing about its paradoxical nature. It on one hand comes through as a means of navigation through the repressive structures and procedures, while on the other ends up bolstering or reinforcing the aspects of structural violence (Galtung, 1969, 1990) of the militarised authoritarian control. Thus, while navigating the direct violence aspects of state repression, rasookh simultaneously ends up buttressing the structural violence aspects of it.

Put simply, as a response to the constraints of formal institutions, rasookh normalises the informal practices of reliance and connection with the same institutions. The various elements of violence (Galtung, 1969, 1990) in the form of observable and unobservable repressions (Earl, 2003) by the state create constraints. The exercise of rasookh in response to that comes through as a means 
of navigating the aforementioned constraints. As such, the normalisation of rasookh for many residents in response to the constraints of zulm of militarised authoritarian control leads to their internalisation (Lawoti, 2008: 29). The process of internalisation helps the state twofold. One, response to the said constraints in the shape of rasookh marks the reliance of the residents on the same formal institutions who's exercise of zulm they endeavour to navigate. This self-sustaining dynamic (Lauth, 2000: 24) becomes reflective of structural violence in the shape of how associating, participating and navigating the constraints of formal institutions, the state draws participation and legitimation from the same people that contend or question its legitimacy. Second, the normalisation and internalisation of such responses increases the efficiency and currency of such responses which sustain or acquiesce the violent institutions. As such, the institutionalisation of these practices prevents many people from overtly challenging and contending the institutions for a positive change. The resort to these informal practices rather contributes and reinforces the status quo that sustains and reinforces the pervading social condition of zulm. As such, through the exercise of rasookh, though the direct violence aspect is navigated, but the structural violence aspect is reinforced which ends up contributing to the sustenance of the overall pervading social condition of zulm.

In light of the arguments made above, the dynamic becomes indicative of how informal institutions may reveal contradictory features of both sustaining and subverting institutional constraints and uncertainties under repressive regimes.

\section{CONCLUSION}

While the paper limits its focus mostly to downtown Srinagar, there is little reason to imagine the prevalence of pervading social conditions like zulm, and the employment of informal institutions like rasookh in relation to zulm to be unique to downtown Srinagar only. Thus, following from the case inductively, it comes through that for the militarised authoritarian state to survive under protracted conflict situations, like Kashmir, reliance on the exercise of observable and unobservable forms of repression (rather than solely depending upon electoral legitimacy) attains significance (Frantz \& Kendall-Taylor, 2014; Gandhi \& Przeworski, 2006). As such, the exercise of repression performs the vital function of countering acts of contention (Tilly, 2006; Tarrow, 2014) by punctuating the physical and social spaces with the militarised authoritarian control argued by Gerschewski as the backbone of survival for militarised authoritarian regimes (Gerschewski, 2013: 21).

Moreover, the paper pinpoints vital aspects of navigating the constraints of militarised authoritarian control under repressive regimes by highlighting the significance of employment of informal institutions (Lauth, 2000: 25). In the context of downtown Srinagar, the employment of informal institution of rasookh by some residents comes through as a significant means of navigating the repressive constraints of zulm. In other words, it helps navigate the precarity that pervades the social and physical spaces as a consequence of the repressive constraints of militarised authoritarian control. However, as argued above, the very act of employing informal institutions with respect to formal institutions, if on one hand navigates the repressive constraints, it simultaneously ends up augmenting its structural violence on the other. Following from there, it may be argued that while navigating the repressive constraints of militarised authoritarian regimes, informal institutions may end up further reinforcing them.

\section{REFERENCES}

Amnesty International. (1992). India: Torture, rapes and deaths in custody. Amnesty International, Bengaluru, India.

Azari, J., \& Smith, J. (2012). Unwritten Rules: Informal Institutions in Established

Democracies. Perspectives on Politics, 10(1), 37-55.

Batool, E., Butt, I., Mushtaq, S., Rashid, M., \& Rather, N. (2016). Do You Remember Kunan Poshpora. New Delhi: Zuban Publications?

Berry, S. (1989). Social Institutions and Access to Resources. Africa: Journal of the International African Institute, 59(1), 41-55.

Brass, P. R. (1997). Theft of an Idol. United States: Princeton University Press.

Brockhill, A., \& Cordell, K. (2019). The violence of culture: the legitimation of the Israeli occupation of Palestine. Third World Quarterly, 40(5), 981998.

Duschinski, H., \& Hoffman, B. (2011). Everyday violence, institutional denial and struggles for justice in 
Kashmir. Race and Class, 52(4), 44-70.

Earl, J. (2003). Tanks, tear gas, and taxes: Toward a theory of movement repression. Sociological Theory, 21(1), 44-68.

Frantz, E., \& Kendall-Taylor, A. (2014). A dictator's toolkit: Understanding how co-optation affects repression in autocracies. Journals.Sagepub.Com, 51(3), 332-346.

Galtung, J. (1969). Violence, peace, and peace research. Journal of Peace Research, 6(3), 167-191.

Galtung, J. (1990). Cultural Violence. Journal of Peace Research, 27(3), 291-305.

Galtung, J. (2007). The State of the World G8 Meeting. Journal of Futures Studies (Vol. 12).

Galtung J., Fischer D. (2013) Violence: Direct, Structural and Cultural. In: Johan Galtung. Springer Briefs on Pioneers in Science and Practice, vol 5. Springer, Berlin, Heidelberg.

Gandhi, J., \& Przeworski, A. (2006). Cooperation, cooptation, and rebellion under dictatorships. Economics and Politics, 18(1), 1-26.

Ganie, M. T. (2021). 'All I got is stones in my hand': youth-led stone pelting protests in Indianadministered Kashmir. Social Movement Studies, 20(1), 115-123.

Geelani, G. (2019). Kashmir Rage and Reason. New Delhi: Rupa Publications India Pvt. Ltd.

Gerschewski, J. (2013). The three pillars of stability: legitimation, repression, and co-optation in autocratic regimes. Democratisation, 20(1), 13-38.

Ghosh, S. N., \& Duschinski, H. (2020). The grid of indefinite incarceration: Everyday legality and paperwork warfare in Indian-controlled Kashmir: 40(3), 364-384.

Harriss-White, B. (2003). India working : essays on society and economy. United Kingdom: Cambridge University Press.

Helmke, G., \& Levitsky, S. (2004). Informal Institutions and Comparative Politics: A Research Agenda. Perspectives on Politics, 2(4), 725-740.

Jeffrey, C. (2000). Democratisation without representation? The power and political strategies of a rural elite in north India. Political Geography, 19(8), 1013-1036.

Jeffrey, C., \& Lerche, J. (2000). Stating the difference: State, discourse and class reproduction in Uttar Pradesh, India. Development and Change, 31(4), 857-878.
Joshi, M. (1998). The lost rebellion. New Delhi: Penguin Random House India Private Limited.

Junaid, M. (2020a). Counter-maps of the ordinary: occupation, subjectivity, and walking under curfew in Kashmir. Identities, 27(3), 302-320.

Junaid, M. (2020b). The price of blood: Counterinsurgency, precarity, and the moral discourse of loyalty in Kashmir. Comparative Studies of South Asia, Africa and the Middle East, 40(1), 166-179.

Kaul, N. (2018). India's obsession with Kashmir: Democracy, gender, (anti-)nationalism. Feminist Review, 119(1), 126-143.

Khan, S. (2008). Local Government Studies Local Governments and Local Elites. Local government studies, 34(4), 509-528.

Krishna, A. (2006). Decentralisation on Fallow and Fertile Ground: Preparing the Population for Democratic Self-Governance,Working Papers id:377, eSocialSciences.

Lauth, H.-J. (2000). Informal Institutions and Democracy. Informal Institutions and Democracy, Democratization, 7(4), 21-50.

Lauth, H.-J. (2004). Informal Institutions and Political Transformation: Theoretical and Methodological Reflections. ECPR Joint Sessions of WorkshopsUppsala (Vol. 18).

Lawoti, M. (2008). Informal Institutions and Exclusion in Democratic Nepal. Himalaya, XXVIII (1-2).

Malik, I. (2002). Kashmir: Domestic Insurgency, International Dispute. Karachi: Oxford University Press

Médecins Sans Frontières (MSF), the University of Kashmir, Institute of Mental Health and Neurosciences (IMHANS). (2016). Muntazar: Kashmir Mental Health Survey Report 2015. MSF, New Delhi, India.

Moss, D. M. (2016). Transnational Repression, Diaspora Mobilization, and the Case of The Arab Spring. Social Problems, 63(4), 480-498.

Neudorfer, N. S., \& Theuerkauf, U. G. (2014). Buying War Not Peace: The Influence of Corruption on the Risk of Ethnic War. Comparative Political Studies, 47(13), 1856-1886.

Osuri, G. (2017). Third World Quarterly Imperialism, colonialism and sovereignty in the (post)colony: India and Kashmir. Third World QuarTerly, 38(11), 2428-2443. 
Pattenden, J. (2011). Gatekeeping as Accumulation and Domination: Decentralization and Class Relations in Rural South India. Journal of Agrarian Change, 11(2), 164-194.

Tarrow, S. (2014). Perspectives on Politics, 12(2), 468470.

The forum for Human Rights in Jammu and Kashmir. (2021). Human rights in Jammu and Kashmir: Midterm report. FHRJK, New Delhi, India

Tilly, C. (1977). Reprtoires of contention in America and Britian. 1750-1830.

Tilly, C. (2003). The Politics of Collective Violence (Cambridge Studies in Contentious
Politics). Spain: Cambridge University Press.

Tilly, C. (2004). Contention and Democracy in Europe, 1650-2000. United Kingdom: Cambridge University Press.

Tilly, C. (2006). Regimes and Repertoires. United states: University of Chicago Press

Utas, M. (2012). African conflicts and informal power: Big men and networks. (M. Utas, Ed.). London: Zed Books Ltd.

Zia, A. (2019). Resisting Disappearance: Military Occupation and Women's Activism in Kashmir. United States: University of Washington Press.

Publisher's note: EScience Press remains neutral with regard to jurisdictional claims in published maps and institutional affiliations.

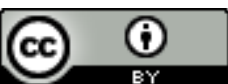
use, sharing, adaptation, distribution and reproduction in any medium or format, as long as you give appropriate credit to the original author(s) and the source, provide a link to the Creative Commons license and indicate if changes were made. The images or other third-party material in this article are included in the article's Creative Commons license, unless indicated otherwise in a credit line to the material. If material is not included in the article's Creative Commons license and your intended use is not permitted by statutory regulation or exceeds the permitted use, you will need to obtain permission directly from the copyright holder. To view a copy of this license, visit http://creativecommons.org/licenses/by/4.0/.

(C) The Author(s) 2021. 